\title{
A TITULARIDADE DOS DIREITOS DE PESSOAS JURÍDICAS: ANÁLISE DO PARECER CONSULTIVO OC 22/16 E A FUNÇÃO INTERPRETATIVA DA CORTE INTERAMERICANA DE DIREITOS HUMANOS
}

\author{
THE OWNERSHIP OF THE RIGHTS OF LEGAL PERSONS: ANALYSIS OF THE \\ ADVISORY OPINION 22/16 AND THE INTERPRETATIVE FUNCTION OF THE INTER- \\ AMERICAN COURT OF HUMAN RIGHTS
}

\author{
Jéssyka Maria Nunes Galvão \\ Advogada. Graduada pela Universidade Federal de Pernambuco (2015). Mestranda no \\ Programa de Pós-Graduação em Direito, UFPE. \\ E-mail: jessyka_nunes@hotmail.com \\ Eugênia Cristina Nilsen Ribeiro Barza \\ Professora Associada, Departamento de Direito Público Especializado, Faculdade de \\ Direito do Recife/Centro de Ciências Jurídicas, Universidade Federal de Pernambuco \\ (UFPE). E-mail: ecnrbarza@terra.com.br
}

Recebido em: 10/03/2017

Aprovado em: 31/07/2017

RESUMO: A chamada competência consultiva da Corte Interamericana desempenha um importante papel na construção dos Direitos Humanos, no âmbito do sistema protetivo regional. Nesse contexto, o Estado do Panamá solicitou opinião interpretativa ao Tribunal concernente ao alcance da Convenção Americana, se esta também salvaguarda os direitos das pessoas jurídicas, considerando-as como legitimadas para acessar a Corte, em defesa de seus próprios interesses. Foi emitido o Parecer OC 22/16, que tratou desta questão, além dos casos especiais das organizações sindicais e comunidades indígenas e, igualmente, decidiu sobre a proteção dos direitos humanos através das pessoas morais e quanto ao exaurimento dos recursos internos por intermédio das pessoas jurídicas. Este trabalho estuda a importância da função interpretativa do Tribunal Interamericano, através da análise da citada opinião consultiva.

Palavras-Chave: Corte Interamericana. Parecer OC 22/16. Pessoas Jurídicas.

ABSTRACT: The so-called advisory jurisdiction of the Inter-American Court plays an important role in the construction of the human rights, within the framework of the regional protection system. In this context, the State of Panama requested an interpretative opinion from the Court concerning the scope of the American Convention, if it also safeguards the rights of legal persons, considering them as entitled to access the Court, in defense of their own interests. The Opinion OC 22/16 was issued, which dealt with this matter, in addition to the special cases of trade union organizations and indigenous communities, and also decided on the protection of human rights through moral persons and on the exhaustion of domestic remedies through the legal persons. This paper studies the importance of the interpretative function of the Inter American Court, through the analysis of the aforementioned advisory opinion.

Keywords: Inter-American Court. Opinion OC 22/16. Legal Persons. 
SUMÁRIO: Introdução; 1. A função consultiva da Corte Interamericana de Direitos Humanos; 2. O Parecer Consultivo OC 22/16; 3. Reflexões sobre o Parecer OC 22/16 e a função consultiva da Corte Interamericana; Conclusão; Referências Bibliográficas.

\section{INTRODUÇÃO}

No âmbito dos sistemas regionais é destacada a importância da Organização dos Estados Americanos (OEA), criada em 1948, congregando 35 Estados membros e constituindo o principal fórum governamental político, jurídico e social da região. A Organização atua conforme os princípios basilares da democracia, dos Direitos Humanos e do desenvolvimento ${ }^{1}$.

No que tange aos Direitos Humanos o instrumento de maior importância e impacto nos países signatários foi o Pacto de São José da Costa Rica. Este, também conhecido como Convenção Americana de Direitos Humanos, foi assinado em 1969, entrando em vigor internacional somente em 1978. Com o intuito de assegurar os direitos correlacionados em tal normativa, foi instituída a Corte Interamericana de Direitos Humanos, como um órgão jurisdicional independente e autônomo em relação à OEA, objetivando a aplicação e interpretação da citada Convenção.

Para garantir que os escopos instituidores da Corte sejam alcançados foram previstos mecanismos como as competências tanto contenciosa como consultiva. Quanto à primeira, na qualidade de um Tribunal de Justiça, a Corte tem o poder de adjudicar disputas relativas à denúncia de que um Estado parte violou a Convenção ${ }^{2}$. Em relação à segunda, a atribuição se relaciona com a interpretação do disposto na Convenção ou de qualquer outro tratado relativo à proteção dos Direitos Humanos aplicável aos Estados americanos. Com base nessa mesma competência, a Corte pode opinar sobre a compatibilidade de preceitos da legislação doméstica em face dos instrumentos internacionais, efetuando o que seria um controle de convencionalidade frente às constituições e normativas internas ${ }^{3}$.

No uso de tal competência interpretativa já foram exarados diversos pareceres de importância para a construção de um sistema regional de proteção dos Direitos Humanos, sendo o mais recente aprovado em 22 de fevereiro de 2016, o qual foi a opinião consultiva de número 22 da Corte. Trata o parecer sobre a possibilidade de pessoas jurídicas serem legítimas para demandar perante o sistema protetivo interamericano e as consequências de tal legitimidade, tendo sido o pedido consultivo efetuado pelo Panamá.

$\mathrm{Na}$ decisão da Corte foram apresentados os questionamentos específicos correlacionados pelo Estado panamenho, gerando a subdivisão do parecer em quatro seções temáticas: primeiro, são esclarecidas as regras gerais sobre a titularidade dos direitos das pessoas jurídicas, em uma perspectiva comparativa com outros sistemas regionais de proteção dos direitos humanos; segundo, são analisados os casos especiais das comunidades indígenas e tribais e as organizações sindicais; terceiro, pela seção sobre a proteção dos direitos humanos das pessoas naturais enquanto membros de pessoas jurídicas; e quarto, com o exaurimento dos recursos internos, como requisito de acesso à Corte, por pessoas jurídicas.

A divisão temática adotada pelo Parecer OC 22/16 será seguida no presente trabalho, sendo sucedida por uma breve análise do voto dissidente do juiz Alberto Pérez Pérez, para chegar-se ao que está sendo aqui proposto, qual seja, estudar a importância da competência

1 ORGANIZAÇÃO DOS ESTADOS AMERICANOS. Página institucional. Disponível em: $<$ http://www.oas.org/pt/sobre/quem_somos.asp>. Acesso em: 23 de fev. de 2017.

${ }^{2}$ BUERGENTHAL, Thomas. Derecho Internacional de los Derechos Humanos: breve visión de los mecanismos. IN: PIOVESAN, Flávia. Direitos Humanos e Justiça Internacional: um estudo comparativo dos Sistemas Regionais Europeu, Interamericano e Africano. 3. ed. rev., ampl. e atual. São Paulo: Saraiva, 2012, p. 139.

${ }^{3}$ PIOVESAN, Flávia. Direitos Humanos e Justiça Internacional: um estudo comparativo dos Sistemas Regionais Europeu, Interamericano e Africano. 3. ed. rev., ampl. e atual. São Paulo: Saraiva, 2012, p. 139-140. 
consultiva da Corte Interamericana na construção dos Direitos Humanos, considerando o reflexo nas jurisdições nacionais dos Estados membros da Convenção Americana.

\section{A FUNÇÃO CONSULTIVA DA CORTE INTERAMERICANA DE DIREITOS HUMANOS}

A Corte possui dois planos de competência atribuídos pela Convenção Americana, um contencioso e outro consultivo. O primeiro é acionado pelos Estados signatários, que tenham aceitado a jurisdição da Corte, em face de casos concretos. Já o segundo é interpretativo, servindo a Corte como órgão de consulta para questionamentos relativos à correta aplicação da Convenção e de outros tratados de Direitos Humanos.

Quanto à atribuição consultiva, de acordo com Olaya Hanashiro: "trata-se de uma função preventiva, de persuasão e colaboração ${ }^{4}$." Assim, conforme o artigo 64 da Convenção:

Os Estados membros da Organização poderão consultar a Corte sobre a interpretação desta Convenção ou de outros tratados concernentes à proteção dos direitos humanos nos Estados americanos. Também poderão consultá-la, no que lhes compete, os órgãos enumerados no Capítulo $\mathrm{X}$ da Carta da Organização dos Estados Americanos, reformada pelo Protocolo de Buenos Aires.

2. A Corte, a pedido de um Estado membro da Organização poderá emitir pareceres sobre a compatibilidade entre qualquer de suas leis internas e os mencionados instrumentos internacionais (OEA, 1969, art. 64).

Percebe-se a amplitude da competência da Corte, pois esta pode analisar não somente questões referentes à Convenção, como também outros tratados e disposições sobre Direitos Humanos, demonstrando, assim, o verdadeiro escopo desse órgão jurisdicional, que é assegurar as garantias e direitos inerentes à condição humana. Igualmente, a Corte poderá, ainda, opinar sobre a compatibilidade dos preceitos da legislação interna nos Estados em face dos instrumentos internacionais, o que pode ser considerado como um controle de convencionalidade abrangendo, principalmente, o âmbito constitucional ${ }^{5}$. Operaria, assim, de acordo com Pedro Nikken, como "uma espécie de tribunal constitucional encarregado de interpretar a Convenção ou qualquer outro tratado de Direitos Humanos ${ }^{6}$."

Considerando o procedimento, os Estados membros da OEA e os órgãos legitimados pelo Capítulo X da Carta da Organização poderão requerer a opinião da Corte, não sendo necessária a existência de um caso concreto. A Corte atuará como órgão jurisdicional e não como assessor jurídico em questões de Direitos Humanos, tem-se em conta que apenas as matérias objeto de consulta têm um caráter mais abstrato ${ }^{7}$. Deve-se frisar, no entanto, que a Corte já consagrou entendimento de que as consultas devem ter uma possível aplicação no caso concreto,

\footnotetext{
${ }^{4}$ HANASHIRO, Olaya Sílvia Portella. O Sistema Interamericano de Proteção aos Direitos Humanos. São Paulo: Universidade de São Paulo/Edusp, 2001, p. 39.

${ }^{5}$ SILVA XAVIER, Heidy de Abreu. O Brasil na Corte Interamericana de Direitos Humanos. Brasília, 2009. Originariamente apresentada como trabalho de conclusão de curso da Universidade Católica de Brasília.

${ }^{6}$ Nikken, Pedro. La Competencia Consultiva de la Corte Interamericana de Derechos Humanos. In: El Sistema Interamericano de Protección de los Derechos Humanos en el Umbral del Siglo XXI. San José de Costa Rica: Corte Interamericana de Derechos Humanos, 2001.

7 CORREIA, Thereza Rachel Couto. Corte Interamericana de Direitos Humanos: repercussão jurídica das opiniões consultivas. Curitiba: Juruá, 2008, p. 138.
}

Revista de Direito Brasileira | São Paulo, SP | v. 19 | n. 8 | p. 170 - 185 |Jan./Abr. 2018 
não podendo ser absolutamente abstratas, pois devem trazer consigo um interesse da região como forma de garantir eficácia social às decisões ${ }^{8}$.

No que tange à legitimidade para formular pedidos de opinião à Corte, existe um número maior de legitimados na competência consultiva do que na contenciosa, pois nesta somente os Estados signatários da Convenção, que reconheçam expressamente a competência da Corte, e a Comissão Interamericana podem submeter casos à decisão do Tribunal. Enquanto que no contexto consultivo, todos os Estados membros da Organização dos Estados Americanos (OEA), possuem titularidade, não importando se ratificaram a Convenção, ou não. Além destes, também são legítimos todos os órgãos presentes no Capítulo X da Carta da OEA, quais sejam: Assembleia Geral; Reunião da Consulta dos Ministros das Relações Exteriores; Conselho Permanente; Conselho Interamericano Econômico, Social e Cultural; Conselho para a Educação, a Ciência e a Cultura; Secretaria Geral; Comissão Interamericana dos Direitos Humanos; Conferências Especializadas; e os Organismos Especializados. Desta lista, somente a Comissão e os Estados membros da OEA podem formular consultas de forma livre, enquanto que os outros órgãos só poderão requerer pareceres relacionados com suas prerrogativas funcionais ${ }^{9}$.

Ao contrário das decisões no contexto da competência contenciosa, as opiniões consultivas não são vinculantes, embora, conforme Pasqualucci, o fato de não serem obrigatórias, ou seja, possuírem coercitividade, não retiraria delas o caráter indiscutivelmente legal e os efeitos morais tanto no direito interno como internacional ${ }^{10}$. Ainda, como a interpretação dada pela Corte no âmbito consultivo é usualmente recorrida para a resolução dos casos contenciosos, os pareceres acabam adquirindo verdadeiro caráter judicial e não meramente científico, de assessoramento ou moral ${ }^{11}$.

\section{O PARECER CONSULTIVO OC 22/16}

Em 28 de abril de 2014 o Estado do Panamá apresentou pedido para a opinião consultiva da Corte Interamericana, o questionamento principal diz respeito à possibilidade das pessoas jurídicas terem legitimação ativa perante a Corte. Os requisitos formais do pedido foram preenchidos, conforme o estabelecido nos artigos 70.1 e 70. 2 do Regulamento do Tribunal, quais sejam:

1. As solicitações de opinião consultiva previstas no artigo 64.1 da Convenção deverão formular com precisão as perguntas específicas sobre as quais pretendem obter a opinião da Corte.

2. As solicitações de opinião consultiva formuladas por um Estado membro ou pela Comissão deverão indicar, ainda, as disposições cuja interpretação se requer, as considerações que originam a consulta e o nome e direção do Agente e dos Delegados (CORTE IDH, 2000, art. 70.1 e 70.2).

Como corolários do argumento central panamenho, foram igualmente formuladas as seguintes perguntas:

1. O artigo 1, parágrafo segundo, da Convenção Americana de Direitos Humanos, restringe a proteção interamericana dos direitos humanos às pessoas físicas e exclui o âmbito de proteção da Convenção às pessoas jurídicas?

\footnotetext{
${ }^{8}$ CORTE INTERAMERICANA DE DIREITOS HUMANOS. Garantías judiciales en estados de emergencia (Arts. 27.2, 25 y 8 Convención Americana sobre Derechos Humanos). Opinião Consultiva OC 9/87 de 6 de outubro de 1987. Serie A No. 9, par. 6. Tradução nossa.

${ }^{9}$ SILVA XAVIER, Heidy de Abreu. O Brasil na Corte Interamericana de Direitos Humanos. Brasília, 2009. Originariamente apresentada como trabalho de conclusão de curso da Universidade Católica de Brasília.

${ }^{10}$ PASQUALUCCI, Jo. M. Advisory Practice of the Inter-American Court of Human Rights: Contributing to the Evolution of International Human Rights Law. 38 STAN. J. INT'L L. 249, (2002). Tradução nossa.

${ }_{11}$ CORREIA, Thereza Rachel Couto. Corte Interamericana de Direitos Humanos: repercussão jurídica das opiniões consultivas. Curitiba: Juruá, 2008, p. 154.
}

Revista de Direito Brasileira | São Paulo, SP | v. 19 | n. 8 | p. 170 - 185 |Jan./Abr. 2018 
2. O artigo 1.2 da Convenção pode proteger também os direitos de pessoas jurídicas cooperativas, sindicatos, associações, sociedades, enquanto compostos por pessoas físicas associadas a essas entidades?

3. Podem as pessoas jurídicas recorrer aos procedimentos da jurisdição interna e exaurir os recursos da jurisdição interna em defesa dos direitos das pessoas físicas titulares dessas pessoas jurídicas?

4. Que direitos humanos podem ser reconhecidos às pessoas jurídicas ou coletivas (não governamentais) no marco da Declaração Americana sobre Direitos Humanos e de seus protocolos ou instrumentos internacionais complementares?

5. No marco da Convenção Americana, além das pessoas físicas, têm as pessoas jurídicas compostas por seres humanos direitos à liberdade de associação do artigo 16, à intimidade e vida privada do artigo 11, à liberdade de expressão do artigo 13 , à propriedade privada do artigo 21 , às garantias judiciais, ao devido processo e à proteção de seus direitos dos artigos 8 e 25 , à igualdade e não discriminação dos artigos 1 e 24, todos da Convenção Americana?

6. Pode uma empresa ou sociedade privada, cooperativa, sociedade civil ou sociedade comercial, um sindicato (pessoa jurídica), um meio de comunicação (pessoa jurídica), uma organização indígena (pessoa jurídica), em defesa de seus direitos e/ou de seus membros, exaurir os recursos da jurisdição interna e recorrer à Comissão Interamericana de Direitos Humanos em nome de seus membros (pessoas físicas associadas ou donas de empresa ou sociedade), ou devem fazê-lo cada membro ou sócio em sua condição de pessoa física?

7. Se uma pessoa jurídica em defesa de seus direitos e dos direitos de seus membros (pessoas físicas associadas ou sócias da mesma) recorrerem à jurisdição interna e esgotarem seus procedimentos jurisdicionais, podem seus membros ou associados recorrerem diretamente à jurisdição internacional da Comissão Interamericana em defesa de seus direitos como pessoas físicas afetadas?

8. No marco da Convenção Americana de Direitos Humanos, as pessoas físicas devem exaurir os recursos da jurisdição interna para recorrer à Comissão Interamericana de Direitos Humanos em defesa de seus direitos humanos, ou podem fazê-lo através das pessoas jurídicas de que participam (CORTE IDH, 2016, p. 5)?

Os Estados da Argentina, Bolívia, Colômbia, El Salvador, Guatemala e Honduras enviaram manifestações escritas para a Corte, fornecendo suas opiniões sobre os questionamentos presentes no pedido consultivo do Panamá. Foi realizada, em 25 de junho de 2015, uma audiência pública com representantes da sociedade civil, Estados e da Comissão Interamericana, decorrendo desta audiência o posicionamento majoritário no sentido contrário à permissão ao acesso das pessoas jurídicas ao Sistema Interamericano ${ }^{12}$.

A Corte inicia a sua decisão a partir do argumento se é possível a consulta sobre a titularidade de direitos das pessoas jurídicas no Sistema Interamericano. Para tal, delimitou o entendimento do Tribunal acerca dos conceitos de pessoa jurídica e legitimação ativa. A respeito do conceito de pessoa jurídica, a Corte recorreu à Convenção Interamericana sobre Personalidade e Capacidade de Pessoas Jurídicas no Direito Internacional Privado de 1984, sendo pessoa jurídica "toda entidade que tenha existência e responsabilidade próprias, distintas das dos seus membros ou fundadores e que seja qualificada como pessoa jurídica segundo a lei do lugar de sua constituição $^{13}$." Já para a legitimação ativa, o embasamento jurídico utilizado foi o do artigo 44

\footnotetext{
${ }^{12}$ VEADO, Luíza Drummond. A Opinião Consultiva 22/16: titularidade de direitos de pessoas jurídicas no Sistema Interamericano. Revista Eletrônica de Direito Internacional, ISSN 1981-9439, vol.19, jul./dez., 2016, pp. 206-230.

13 ORGANIZAÇÃO DOS ESTADOS AMERICANOS. Convenção Interamericana sobre Personalidade $e$ Capacidade de Pessoas Jurídicas no Direito Internacional Privado, 1984.

Revista de Direito Brasileira | São Paulo, SP | v. 19 | n. 8 | p. 170 - 185 |Jan./Abr. 2018
} 
da Convenção Americana, o qual permite a qualquer pessoa ou grupo de pessoas, ou ainda entidade não governamental reconhecida por algum dos Estados membros da OEA, possa apresentar à Comissão petições que contenham denúncias ou queixas de violação da Convenção por um Estado membro ${ }^{14}$.

$\mathrm{O}$ primeiro ponto a ser analisado no parecer se refere à interpretação do artigo 1.2 da Convenção Americana, o qual preceitua que "para os efeitos da Convenção, pessoa é todo ser humano ${ }^{15}$." A Corte buscou na Convenção de Viena sobre Direitos dos Tratados de $1969^{16}$ a base interpretativa para responder as questões 1 e 2 do pedido do Panamá. A dita Convenção dispõe que os tratados deverão ser interpretados conforme a boa fé, em seu sentido corrente de que foi atribuído os termos do tratado, no contexto destes e tendo em conta o seu objeto e fim ${ }^{17}$. Assim, o Tribunal analisou: o sentido corrente do termo boa fé; o objeto e fim da Convenção Americana; o contexto interno desta e a sua interpretação evolutiva ${ }^{18}$.

Em relação ao sentido da palavra pessoa, a Corte citou o dicionário da Real Academia Espanhola, o qual traz a acepção de pessoa como "indivíduo da espécie humana ${ }^{19}$." Após o entendimento literal, o Tribunal passou para a interpretação teleológica em relação ao objeto e fim da Convenção Americana ${ }^{20}$, o que seria a proteção dos direitos fundamentais dos seres humanos, excluindo as pessoas jurídicas do âmbito protetivo. ${ }^{21} \mathrm{Em}$ uma análise sistemática, a Corte analisou o Sistema Interamericano e, inclusive, outros artigos da Convenção em discussão, e ratificou que o termo pessoa só poderia abranger as pessoas físicas, e não as jurídicas ${ }^{22}$. Da mesma forma, também analisou outros sistemas regionais, em uma interpretação evolutiva, dos Sistemas Europeu e Africano de Direitos Humanos, além do posicionamento da Organização das Nações Unidas e outros ordenamentos jurídicos internos.

Em breve síntese, foi discutido se o Sistema Europeu entende as pessoas jurídicas como legítimas para acessarem as cortes europeias ${ }^{23}$, desde que o centro da petição seja, de fato, a pessoa moral, e não as pessoas físicas que a compõem ${ }^{24}$. O que não seria permitido no Sistema Interamericano, pois a referência presente no artigo 44 da Convenção Americana, "organização não governamental ou grupo de particulares", não infere em uma autorização para as pessoas jurídicas acessarem o sistema ${ }^{25}$.

${ }^{14}$ ORGANIZAÇÃO DOS ESTADOS AMERICANOS. Convenção Americana sobre Direitos Humanos, 1969, artigo 44.

${ }^{15}$ Ibid., artigo 1.2 .

${ }^{16}$ ORGANIZAÇÃO DAS NAÇÕES UNIDAS. Convenção de Viena sobre o Direito dos Tratados, 1969, artigos 31 e 32 .

${ }^{17}$ ORGANIZAÇÃO DAS NAÇÕES UNIDAS, Convenção Americana sobre Direitos Humanos, 1969, artigo 31. Tradução nossa.

${ }^{18}$ CORTE INTERAMERICANA DE DIREITOS HUMANOS, Parecer Consultivo OC 22/16 de 26 de fevereiro de 2016, par. 36. Tradução nossa.

${ }^{19}$ Diccionario de la lengua española de la Real Academia Española, 23. ${ }^{a}$ ed. Madrid: Espanha, 2014. Disponível em: http://dle.rae.es/?id=SjUIL8Z. Tradução nossa.

${ }^{20}$ CORTE INTERAMERICANA DE DIREITOS HUMANOS. El efecto de las reservas sobre la entrada em vigencia de la Convención Americana sobre Derechos Humanos. Opinião Consultiva OC-2/82 de 24 de setembro de 1982. Serie A No. 2, par. 29. Tradução nossa.

${ }^{21}$ VEADO, Luíza Drummond. A Opinião Consultiva 22/16: titularidade de direitos de pessoas jurídicas no Sistema Interamericano. Revista Eletrônica de Direito Internacional, ISSN 1981-9439, vol.19, jul./dez., 2016, pp. 206-230.

${ }^{22}$ CORTE INTERAMERICANA DE DIREITOS HUMANOS. Parecer Consultivo OC 22/16 de 26 de fevereiro de 2016, par. 48. Tradução nossa.

${ }^{23}$ Cfr. CONSELHO DA EUROPA. Convenção Europeia dos Direitos Humanos, 1950, artigo 34. CONSELHO DA EUROPA. Protocolo Adicional à Convenção Europeia dos Direitos Humanos, 1952, artigo 1.

${ }^{24}$ CORTE INTERAMERICANA DE DIREITOS HUMANOS. Parecer Consultivo OC 22/16 de 26 de fevereiro de 2016, par. 55. Tradução nossa.

${ }^{25}$ Ibid., par. 56.

Revista de Direito Brasileira | São Paulo, SP | v. 19 | n. 8 | p. 170 - 185 |Jan./Abr. 2018 
Quanto ao sistema africano, a Carta Africana sobre os Direitos Humanos e dos Povos de $1981^{26}$ não oferece nenhuma definição sobre o termo pessoa ou sobre o que seria povos. Assim como no sistema interamericano, a Carta Africana confere às pessoas jurídicas a capacidade de apresentar comunicações à Comissão Africana, ou seja, podem denunciar violações aos direitos humanos, em nome de terceiros, mas não poderiam acessar diretamente as Cortes em benefício de seus próprios interesses ${ }^{27}$.

Já no âmbito universal o Pacto Internacional de Direitos Civis e Políticos de $1966^{28}$ igualmente não é extensivo às pessoas jurídicas, ou seja, somente indivíduos podem denunciar, em nome próprio, perante o Comitê de Direitos Humanos ${ }^{29}$. Todavia, a Convenção Internacional sobre a Eliminação de todas as formas de Discriminação Racial de $1965^{30}$ é uma exceção, pois permite que as pessoas jurídicas possam elaborar denúncias que afetem seus direitos, sempre que se considerarem vítimas do caso, ou em nome dos seus membros, acionistas e proprietários, tanto individualmente, como coletivamente ${ }^{31}$.

Em suma, ao analisar os sistemas universal e regional, o Tribunal chegou à conclusão de que a maioria dos modelos só estabelece como legitimados à ação os indivíduos, não as pessoas morais, salvo o Sistema Europeu e a Convenção sobre Discriminação Racial de $1965^{32}$.

A Corte fez uma análise das legislações internas dos países membros da OEA, em relação em ao tratamento jurídico estabelecido por estes países no que diz respeito à legitimação ativa das pessoas jurídicas para acionarem as respectivas jurisdições nacionais. Tal estudo chegou à conclusão de que a maior parte destes países outorga às pessoas jurídicas a possibilidade de interpor ações em defesa dos seus direitos, em nome próprio ${ }^{33}$.

Apesar disto, o Tribunal entendeu que não seria suficiente este fato para que a Corte também conferisse igual titularidade, uma vez que não existe uma uniformidade entre os Estados na aplicação da temática ${ }^{34}$. Finalizando a seção, o parecer recorre novamente à Convenção de Viena de $1969^{35}$ no que tange aos meios complementares de interpretação, em especial os trabalhos preparatórios. Estes confirmam a interpretação da Corte, pois foram utilizados os termos pessoa e ser humano sem distinção na confecção da Convenção Americana ${ }^{36}$.

Foi estabelecido, então, que a Convenção Americana não atribui às pessoas jurídicas a titularidade perante o Tribunal. Mesmo assim, o Estado do Panamá também questionou sobre a possibilidade de tal legitimidade ser conferida às comunidades indígenas e tribais e às organizações sindicais. Quanto às primeiras, já existia jurisprudência da Corte Interamericana permitindo a estas o acesso ao sistema, podendo apresentar pedidos quanto aos seus direitos e dos seus membros ${ }^{37}$.

${ }^{26}$ ORGANIZAÇÃO DA UNIDADE AFRICANA. Carta Africana dos Direitos Humanos e dos Povos, 1981.

${ }^{27}$ CORTE INTERAMERICANA DE DIREITOS HUMANOS. Parecer Consultivo OC 22/16 de 26 de fevereiro de 2016, par. 57 e 58.

${ }^{28}$ ORGANIZAÇÃO DAS NAÇÕES UNIDAS. Pacto Internacional dos Direitos Civis e Políticos, 1966.

${ }^{29}$ CORTE INTERAMERICANA DE DIREITOS HUMANOS. Parecer Consultivo OC 22/16 de 26 de fevereiro de 2016, par. 59.

${ }^{30}$ ORGANIZAÇÃO DAS NAÇÕES UNIDAS. Convenção Internacional sobre a Eliminação de todas as formas de Discriminação Racial, 1965.

${ }^{31}$ CORTE INTERAMERICANA DE DIREITOS HUMANOS. Parecer Consultivo OC 22/16 de 26 de fevereiro de 2016, par. 60.

32 VEADO, Luíza Drummond. A Opinião Consultiva 22/16: titularidade de direitos de pessoas jurídicas no Sistema Interamericano. Revista Eletrônica de Direito Internacional, ISSN 1981-9439, vol.19, jul./dez., 2016, pp. 206-230.

${ }^{33}$ CORTE INTERAMERICANA DE DIREITOS HUMANOS. Parecer Consultivo OC 22/16 de 26 de fevereiro de 2016, par. 65.

${ }^{34}$ Ibid., par. 67.

${ }^{35}$ ORGANIZAÇÃO DAS NAÇÕES UNIDAS. Convenção de Viena sobre o Direito dos Tratados, 1969, artigo 31.

${ }^{36}$ CORTE INTERAMERICANA DE DIREITOS HUMANOS, Parecer Consultivo OC 22/16 de 26 de fevereiro de 2016, par. 68.

${ }^{37}$ CORTE INTERAMERICANA DE DIREITOS HUMANOS. Parecer Consultivo OC 22/16 de 26 de fevereiro de 2016, par. 72. Tradução nossa.

Revista de Direito Brasileira | São Paulo, SP | v. 19 | n. 8 | p. 170 - 185 |Jan./Abr. 2018 
Em uma primeira etapa, só eram considerados como sujeitos de direito os membros das comunidades, e não esta como coletividade ${ }^{38}$. A partir do ano de 2012, no caso do Povo Indígena Kichwa de Sarayaku Vs Equador, foi reconhecida a comunidade indígena como titular dos direitos protegidos, e não os membros através desta ${ }^{39}$. Nesta sentença, foi considerado que os direitos do povo indígena Kichwa fora violado, nos aspectos da propriedade comum, da identidade cultural, das garantias judiciais e da proteção judicial, considerando-se o Estado o responsável por colocar em risco os direitos à vida e integridade física dos membros da comunidade. Nesse ensejo, a Corte entendeu que existem alguns direitos que estes membros gozam por si mesmos, enquanto que existem outras garantias cujo exercício se dá de forma coletiva, através das comunidades ${ }^{40}$. Assim, esclarece Flávia Piovesan que:

à luz de uma interpretação evolutiva e dinâmica, reconheceu a Corte os direitos dos povos indígenas à propriedade coletiva da terra, como uma tradição comunitária, e como direito fundamental e básico a sua cultura, vida espiritual, integridade e sobrevivência econômica. Acrescentou que para os povos indígenas a relação com a terra não é somente uma questão de possessão e produção, mas um elemento material e espiritual de que devem gozar plenamente, inclusive para preservar seu legado cultural e transmiti-lo às gerações futuras (PIOVESAN, 2012, p. 168).

Portanto, a Corte permite o acesso das comunidades indígenas e tribais ao sistema protetivo para defender esses ditos direitos que lhe são inerentes como coletividade, não sendo necessária a intermediação do pedido via Comissão Interamericana.

Quanto às organizações sindicais, federações e confederações o questionamento panamenho tem relevância devido ao colacionado no artigo 8.1 do Protocolo de São Salvador de 1988, qual seja, os direitos de livre organização e filiação, assim como o de livre funcionamento $^{41}$. No artigo 19.6, o Protocolo determina que:

Caso os direitos estabelecidos na alínea $a$ do artigo 8 e no artigo 13, forem violados por ação imputável diretamente a um Estado Parte deste Protocolo, essa situação poderia dar lugar, mediante participação da Comissão Interamericana de Direitos Humanos e, quando cabível, da Corte Interamericana de Direitos Humanos, à aplicação do sistema de petições individuais regulado pelos artigos 44 a 51 e 61 a 69 da Convenção Americana sobre Direitos Humanos (OEA, 1988, art. 8.1).

A partir de tal estipulação, o parecer da Corte analisou o âmbito protetivo conferido aos sindicatos a partir do citado Protocolo para determinar se estes possuem legitimidade perante o Tribunal. Foi destacado que o dito Protocolo faz parte da Convenção Americana e, por conseguinte,

\footnotetext{
${ }^{38}$ Cfr. Caso de la Comunidad Mayagna (Sumo) Awas Tingni Vs. Nicaragua. Fondo, Reparaciones y Costas. Sentença de 31 de agosto de 2001. Serie C No. 79; Caso de la Comunidad Moiwana Vs. Surinam. Excepciones Preliminares, Fondo, Reparaciones y Costas. Sentença de 15 de junho de 2005. Serie C No. 124; Caso Comunidad Indígena Yakye Axa Vs. Paraguay. Fondo Reparaciones y Costas. Sentença de 17 de junho de 2005. Serie C No. 125; Caso Comunidad Indígena Sawhoyamaxa Vs. Paraguay. Fondo, Reparaciones y Costas. Sentença de 29 de março de 2006. Serie C No. 146; Caso del Pueblo Saramaka. Vs. Surinam. Excepciones Preliminares, Fondo, Reparaciones y Costas. Sentença de 28 de novembro de 2007. Serie C No. 172, y Caso Comunidad Indígena Xákmok Kásek. Vs. Paraguay. Fondo, Reparaciones y Costas. Sentença de 24 de agosto de 2010 Serie C No. 214.

${ }^{39}$ Cfr. Caso Pueblo Indígena Kichwa de Sarayaku Vs. Ecuador. Fondo y reparaciones. Sentença de 27 de junho de 2012. Serie C No. 245, pontos declarativos 2 a 4.

${ }^{40}$ CORTE INTERAMERICANA DE DIREITOS HUMANOS. Parecer Consultivo OC 22/16 de 26 de fevereiro de 2016, par. 73 e 74.

${ }^{41}$ ORGANIZAÇÃO DOS ESTADOS AMERICANOS. Protocolo Adicional à Convenção Americana sobre Direitos Humanos em Matéria de Direitos Econômicos, Sociais e Culturais, 1988, artigo 8.1.
}

Revista de Direito Brasileira | São Paulo, SP | v. 19 | n. 8 | p. 170 - 185 |Jan./Abr. 2018 
obedece ao princípio pro persona estipulado por esta. Logo, a interpretação deverá ser a mais garantista, não excluindo o efeito que podem ter outros instrumentos como, por exemplo, a Carta da $\mathrm{OEA}^{42}$. Esta reconhece direitos às associações de empregadores e trabalhadores e faz remissão à Declaração da Organização Internacional do Trabalho de $1998^{43}$ quanto ao respeito da liberdade sindical, a qual enseja não somente o direito de livre associação dos trabalhadores, como garante às organizações sindicais a prerrogativa de livre funcionamento ${ }^{44}$. A proteção de tais direitos associativos desses entes coletivos garante, em sua essência, a efetividade da prerrogativa dos trabalhadores em se associarem livremente ${ }^{45}$.

A Corte entendeu que a interpretação mais favorável do Protocolo de São Salvador de 1988 consiste em que neste estão consagrados direitos a favor dos sindicatos, federações e confederações, uma vez que estes são interlocutores de seus associados. O Protocolo especifica, ainda, que o acesso das organizações sindicais ao Tribunal Interamericano só seria aplicável com base no artigo 8.1, quando os direitos nele presentes forem violados por uma ação imputável diretamente a um Estado membro da Convenção. Assim, a Corte conclui que os sindicatos, federações e confederações são legitimados para defenderem os direitos supra referidos, em nome próprio $^{46}$.

Após analisar os casos especiais, o parecer consultivo buscou responder às perguntas de números 4 e 5 propostas pelo Panamá, referentes ao exercício dos direitos das pessoas naturais através das pessoas jurídicas. Foi ressaltado que em muitas situações em que a pessoa ficta interpõe a ação alegando defender seus interesses, reflexamente seriam protegidos os direitos das pessoas físicas representadas pela pessoa moral ${ }^{47}$. Contudo, trata-se de uma análise casuística em que o Tribunal verifica no caso concreto se, efetivamente, a pessoa física exerceu seu direito através da ficção da pessoa jurídica. Ainda; é considerado se existe uma relação direta entre o indivíduo que requer a proteção e a pessoa jurídica através da qual foi produzida a violação, pois este vínculo não pode ser tênue, uma vez que se visa assegurar as garantias da pessoa natural, não da pessoa moral ${ }^{48}$.

Assim, a Corte Interamericana entende ser possível que através de uma pessoa jurídica sejam exercidos os direitos da pessoa física, no entanto, não existiria um padrão, pois existem diversas situações possíveis, restringindo as decisões do Tribunal à verificação dos casos concretos $^{49}$.

A última seção temática do parecer corresponde às perguntas 3,6,7 e 8 do pedido opinativo panamenho e diz respeito ao exaurimento dos recursos internos por pessoas jurídicas, em seu nome ou representando seus membros. O artigo 46.1 da Convenção Americana dispõe sobre os requisitos de admissibilidade para acessar a Corte, entre estes está presente a necessidade de interposição e exaurimento (ou esgotamento) dos recursos no âmbito da jurisdição interna ${ }^{50}$.

Tal requisito é devido à natureza complementar do Direito Internacional Público sendo, primeiramente, responsabilidade do Estado resolver as questões de violações de direitos humanos

\footnotetext{
${ }^{42}$ ORGANIZAÇÃO DOS ESTADOS AMERICANOS. Carta da Organização dos Estados Americanos, 1967, artigos 10 e 45.

${ }^{43}$ ORGANIZAÇÃO INTERNACIONAL DO TRABALHO. Declaração da Organização Internacional do Trabalho sobre os princípios e direitos fundamentais no trabalho e seu seguimento, 1998.

${ }^{44}$ CORTE INTERAMERICANA DE DIREITOS HUMANOS. Parecer Consultivo OC 22/16 de 26 de fevereiro de 2016, par. 95. Tradução nossa.

${ }^{45}$ Ibid., par. 96. Tradução nossa.

${ }^{46}$ Ibid., par. 103 e 105. Tradução nossa.

${ }^{47}$ Cfr. Caso Cantos Vs. Argentina. Excepciones Preliminares, par. 29, Caso Granier y otros (Radio Caracas Televisión) Vs. Venezuela, par. 146.

${ }^{48}$ CORTE INTERAMERICANA DE DIREITOS HUMANOS. Parecer Consultivo OC 22/16 de 26 de fevereiro de 2016, par. 118 e 119. Tradução nossa.

${ }^{49}$ VEADO, Luíza Drummond. A Opinião Consultiva 22/16: titularidade de direitos de pessoas jurídicas no Sistema Interamericano. Revista Eletrônica de Direito Internacional, ISSN 1981-9439, vol.19, jul./dez., 2016, pp. 206-230.

${ }^{50}$ ORGANIZAÇÃO DOS ESTADOS AMERICANOS. Convenção Americana sobre Direitos Humanos, 1969, artigo 46.1.
} 
suscitadas. O parecer traz à colação os critérios reiterados na jurisprudência da Corte como demonstrativos do exaurimento da jurisdição interna, quais sejam: a disponibilidade, idoneidade e efetividade dos tribunais nacionais, na defesa dos direitos em questão ${ }^{51}$.

Analisando o artigo 46.1, foi constatado que a interpretação dada a este não pode limitar o acesso ao Sistema Interamericano, assim seria desproporcional exigir a interposição de recursos inexistentes, quando comprovado que foram utilizados os recursos idôneos e efetivos, exauridos através da pessoa jurídica. Estabelece o parecer que se através de um recurso em sede interna, que foi interposto por uma pessoa jurídica, se protegiam os direitos das pessoas naturais, logo, não existiria razão para a Corte não entender como preenchido o requisito do esgotamento da jurisdição interna $^{52}$. Em síntese, serão considerados como exauridos os recursos internos quando:

1. Seja comprovado que foram apresentados os recursos disponíveis, idôneos e efetivos para a proteção de seus direitos, independentemente se ditos recursos tenham sido apresentados e resolvidos em favor de uma pessoa jurídica.

2. For demonstrado que existe uma coincidência entre as pretensões que a pessoa jurídica alegou nos procedimentos internos e as presumidas violações que se argumentem perante o Sistema Interamericano (CORTE IDH, 2016, p. 45).

A decisão do Tribunal exarou que a ação de uma pessoa jurídica, através da qual atua uma pessoa natural (interessada no caso em questão), não deve constituir um obstáculo, ou desculpa, para que o Estado deixe de cumprir com as referidas obrigações protetivas ${ }^{53}$. Não existirá, portanto, tal óbice para que as vítimas da violação em comento possam requisitar à Corte a efetividade dos seus direitos perante a figura estatal.

Cabe ainda colacionar, sinteticamente, o teor da decisão pretoriana, configurando a opinião consultiva da Corte a respeito das perguntas formuladas pelo Estado do Panamá:

1. O artigo 1.2 da Convenção Americana só consagra direitos em favor das pessoas físicas, razão pela qual as pessoas jurídicas não são titulares dos direitos consagrados em dito tratado.

2. As comunidades indígenas e tribais são titulares dos direitos protegidos pela Convenção e, portanto, podem acionar o Sistema Interamericano.

3. O artigo 8.1 do Protocolo de São Salvador outorga titularidade de direitos aos sindicatos, federações e confederações, os quais lhes permitem acessar o Sistema Interamericano para a defesa de seus próprios direitos, consagrados no referido artigo.

4. As pessoas físicas em alguns casos podem exercer seus direitos através das pessoas jurídicas, de maneira que em ditas situações possam recorrer ao Sistema Interamericano para apresentar as presumidas violações a seus direitos.

5. As pessoas físicas sob certos supostos podem exaurir os recursos internos mediante recursos interpostos pelas pessoas jurídicas (CORTE IDH, 2016, p. 4647).

A referida decisão não foi tomada de forma unânime, existindo um voto dissidente através do juiz Alberto Pérez Pérez. Este concordou com a impossibilidade das pessoas jurídicas serem consideradas como legítimas para interporem perante a Corte, assim como votou favoravelmente no que diz respeito à titularidade de direitos coletivos conferida às comunidades indígenas e tribais. Contudo, o magistrado argumentou que quanto aos sindicatos e outras associações, não estariam

${ }^{51}$ CORTE INTERAMERICANA DE DIREITOS HUMANOS. Parecer Consultivo OC 22/16 de 26 de fevereiro de 2016, par. 127. Tradução nossa.

52 CORTE INTERAMERICANA DE DIREITOS HUMANOS. Parecer Consultivo OC 22/16 de 26 de fevereiro de 2016, par. 133 e 134. Tradução nossa.

${ }^{53}$ Ibid., par. 140. Tradução nossa.

Revista de Direito Brasileira | São Paulo, SP | v. 19 | n. 8 | p. 170 - 185 |Jan./Abr. 2018 
sendo protegidos os direitos destas enquanto pessoas jurídicas, mas sim os direitos das pessoas físicas que as compõem, logo votou contrariamente à opinião da Corte nesse sentido. Pois aos indivíduos prejudicados deve ser conferida a legitimidade ativa, não às pessoas morais intermediárias.

$\mathrm{Na}$ mesma lógica não é possível a proteção dos direitos humanos através da pessoa jurídica, pela razão de que cabe ao titular do direito acionar o sistema, portanto, deve ser realizado pelo indivíduo, em seu nome. Igualmente votou de forma contrária ao entendimento pretório sobre o esgotamento dos recursos internos através das pessoas jurídicas por entender que esta é uma prerrogativa exclusiva da pessoa física, em seu próprio nome. A pessoa fictícia não seria titular dos direitos presentes na Convenção Americana, logo, não pode substitui-la processualmente no âmbito da Corte ${ }^{54}$.

\section{REFLEXÕES SOBRE O PARECER OC 22/16 E A FUNÇÃO CONSULTIVA DA CORTE INTERAMERICANA}

A competência consultiva da Corte foi estruturada com intuito de abranger não somente a Convenção Americana, mas ainda outros tratados concernentes à proteção dos direitos humanos, assim como existe a possibilidade de ser solicitada a opinião acerca da compatibilidade da legislação interna dos países membros da OEA com tais tratados ou com o Pacto de São José da Costa Rica, em uma espécie de controle de convencionalidade. Nesta função interpretativa não existem partes ou demandados e nenhum Estado é requerido para defender-se contra acusações formais, nem sanção alguma é prevista. Este procedimento de consulta é destinado unicamente a facilitar a obtenção de uma interpretação judicial, a pedido de um dos Estados membros ou, ainda, por algum dos órgãos da OEA, legitimados para tal ${ }^{55}$.

No exercício desta função, a Corte não é chamada para resolver questões de fato, mas sim explorar o sentido, propósito e razão das normas internacionais sobre os direitos humanos ${ }^{56}$. Segundo Cançado Trindade: "a Corte Interamericana exerce a importante função de interpretação da letra e espírito da Convenção Americana sobre Direitos Humanos ${ }^{57}$." E, apesar dos pareceres emitidos não possuírem caráter vinculante, os efeitos jurídicos destes são inegáveis ${ }^{58}$, uma vez que se tratam, na verdade, de fonte interpretativa para a jurisprudência do próprio Tribunal, em sua competência contenciosa, a qual emana decisões obrigatórias.

O caso da Opinião Consultiva OC 22/16, objeto da presente análise, advém da mesma necessidade, uma vez que o Estado do Panamá formulou pedido interpretativo a respeito da abrangência da legitimidade para interpor perante a Corte. A dúvida principal envolve a possibilidade das pessoas jurídicas serem consideradas como titulares de tal prerrogativa, conforme margem de interpretação que poderia ser conferida à Convenção Americana. Nota-se nesta situação que o Estado atua como intermediário perante o Sistema Interamericano visando não um pedido concernente à situação exclusiva nacional, mas sim existe uma preocupação com o âmbito protetivo dos direitos humanos na região, buscando o melhor funcionamento do sistema e, em essência da proteção do ser humano, e não dos nacionais de tal país.

\footnotetext{
${ }^{54}$ CORTE INTERAMERICANA DE DIREITOS HUMANOS. Parecer Consultivo OC 22/16 de 26 de fevereiro de 2016, voto dissidente do juiz Pérez Pérez. Tradução nossa.

${ }^{55}$ CORTE INTERAMERICANA DE DIREITOS HUMANOS. Opinião Consultiva OC 3/83 de 8 de setembro de 1983, par. 22. Tradução nossa.

${ }^{56}$ CORTE INTERAMERICANA DE DIREITOS HUMANOS. Opinião Consultiva OC $16 / 99$ de 1 de outubro de 1999, par. 47. Tradução nossa.

${ }^{57}$ TRINDADE, Antônio Augusto Cançado. Tratado de Direito Internacional dos Direitos Humanos. Vol. II. Porto Alegre: Sergio Antônio Fabris Editor, 1999.

${ }^{58}$ CORTE INTERAMERICANA DE DIREITOS HUMANOS. Opinião Consultiva OC 17/02 de 28 de agosto de 2002, par. 33. Tradução nossa.
}

Revista de Direito Brasileira | São Paulo, SP | v. 19 | n. 8 | p. 170 - 185 |Jan./Abr. 2018 
A opinião consultiva decorrente de tal pedido refletiu exatamente esta preocupação, qual seja a de explorar o alcance da norma internacional tendo como escopo promover o prosseguimento na construção dos Direitos Humanos. Esta finalidade determinou a decisão pretória, no sentido que foi negada a titularidade de direitos, perante a Convenção, às pessoas jurídicas, tendo em vista que não pode a Corte imiscuir-se na defesa de direitos referentes exclusivamente à pessoa fictícia, sob pena de perder-se a essência do sistema, que é a proteção da pessoa humana. Tal entendimento ficou claro no parecer referido, da seguinte forma:

a Corte considera que o Preâmbulo da Convenção Americana, assim como as primeiras considerações da Declaração Americana, mostram que estes instrumentos foram criados com a intenção de centrar a proteção e titularidade dos direitos no ser humano. Do anterior se infere pela constante referência a palavras como "homem" ou "pessoa humana", as quais denotam que não se estava tendo em conta a figura das pessoas jurídicas na hora de redigir ditos instrumentos (CORTE IDH, 1999, par. 47).

No parecer não se buscou questionar a natureza das pessoas jurídicas, se estas como pessoas fictícias teriam direitos exclusivos, entre outros questionamentos. O objetivo reside no alcance desses direitos, ou seja, se a Convenção também os abarcaria garantindo, assim, a legitimidade ativa das pessoas morais diante do sistema. A decisão da Corte só preceitua as exceções: das organizações sindicais e outras associações, na defesa de seus direitos quanto ao livre funcionamento; e das comunidades indígenas e tribais no que diz respeito aos seus direitos coletivos. No entanto, percebe-se que mesmo tais exceções tem como escopo a salvaguarda dos direitos das pessoas físicas que são parte dos citados exemplos.

Apesar das pessoas jurídicas não serem as titulares dos direitos instituídos na Convenção, estas podem atuar diante da Comissão ou da Corte como representantes de pessoas físicas ${ }^{59}$. Assim, as Organizações não Governamentais e escritórios de advocacia podem ter o papel de assessoramento dos interessados que desejam interpor diante do Tribunal Interamericano ${ }^{60}$.

A influência das opiniões da Corte não abrange somente o sistema regional protetivo, como tem importante papel nas jurisdições nacionais, nesse sentido:

A atuação da Corte Interamericana de Direitos Humanos tem o propósito de complementar a proteção existente no direito interno, suprindo as omissões ou reprimindo as ações do Estado violadoras desses direitos. Tem, também, a função de alertar e denunciar a desídia dos governantes em relação ao dever de assegurar a plenitude dos direitos humanos. (...) É necessário reconhecer no indivíduo a razão de ser do Estado. A prevalência da norma internacional de direitos humanos em face do ordenamento jurídico interno não é um fato desconhecido, nem distante da realidade jurídica no nosso continente. (...) A jurisprudência da Corte Interamericana de Direitos Humanos reconhece que a adoção de leis internas incompatíveis com a Convenção implica responsabilidade internacional do Estado (JAYME, 2008, p. 90 e 97).

Tem-se que não somente a competência contenciosa exerce influência nos Estados, mas também a consultiva tem relevante papel nesse sentido, uma vez que se faz igualmente necessário considerar que há certa pressão internacional diante dos Estados, que pedem a opinião interpretativa da Corte. Esta assegurou desde a sua criação uma posição predominante na

\footnotetext{
59 ORGANIZAÇÃO DOS ESTADOS AMERICANOS. Convenção Americana sobre Direitos Humanos, 1969, artigo 46.

${ }^{60}$ VEADO, Luíza Drummond. A Opinião Consultiva 22/16: titularidade de direitos de pessoas jurídicas no Sistema Interamericano. Revista Eletrônica de Direito Internacional, ISSN 1981-9439, vol.19, jul./dez., 2016, pp. 206-230.
}

Revista de Direito Brasileira | São Paulo, SP | v. 19 | n. 8 | p. 170 - 185 |Jan./Abr. 2018 
construção dos Direitos Humanos na região americana, o que faz com que diante de suas decisões, ou opiniões, exista um grau de respeitabilidade dificultando, assim, o não cumprimento estatal. Apesar disto, Flávia Piovesan aponta que "as fragilidades e insuficiências do sistema revelam, sobretudo, as fragilidades e insuficiências da proteção dos direitos humanos no âmbito interno dos Estados ${ }^{61}$." Tais ponderações apenas demonstram a importância da função consultiva da Corte diante de uma região com constituições e ordenamentos jurídicos ainda frágeis na proteção das garantias humanas, exercendo, assim, a Corte um relevante papel de guia interpretativo, em uma espécie de controle de convencionalidade. Neste controle, as normativas internas passam pelo crivo de compatibilidade com os instrumentos internacionais, verificando a sua adequação e conformidade.

\section{CONCLUSÃO}

Com a consolidação dos sistemas universal e regional de proteção, tem-se percebido que não mais apenas sob o prisma moral e político torna-se possível a defesa dos direitos humanos. Existe uma crescente judicialização da temática notando-se que, diante dos sistemas protetivos dos direitos humanos, a Corte Interamericana tem se destacado como uma instituição que garante tais direitos, utilizando, principalmente, o marco jurídico da Convenção Americana de Direitos Humanos de 1969 ou, mais conhecido como Pacto de São José da Costa Rica.

A estrutura da Corte permite que esta possua duas modalidades de competência: uma contenciosa outra consultiva. Sendo a primeira acionada diante de um caso concreto de violação de direitos humanos em face de um Estado. No que é pertinente à outra prerrogativa, esta se trata de uma função ligada à interpretação da própria Convenção, mas ainda podendo ser formulados questionamentos com base em outros instrumentos internacionais, com a temática da defesa dos direitos humanos.

Diante de tal competência, o Estado do Panamá formulou um pedido de opinião consultiva à Corte, que emitiu o parecer OC 22/16, que trata sobre a titularidade de direitos de pessoas jurídicas no Sistema Interamericano. A dúvida principal concerne em relação à abrangência da Convenção, principalmente em relação ao sentido do termo pessoa utilizado naquela, se poderia dar ensejo à legitimidade ativa das pessoas jurídicas. Com base nos métodos clássicos de interpretação, o Tribunal opinou no sentido negativo, ou seja, que as pessoas jurídicas não são titulares dos direitos referidos na Convenção. Ainda, foi decidido que existem exceções a este entendimento, presentes nos casos especiais das organizações sindicais e das comunidades indígenas e tribais. Tais entes possuiriam direitos exclusivamente coletivos, o que atribui a estes a prerrogativa de acessarem a Corte em defesa de seus interesses, e nos limites abarcados pelo parecer em comento. O Estado do Panamá também questionou se seria possível que os direitos das pessoas físicas possam ser protegidos por intermédio de pessoas jurídicas; sendo a resposta da Corte favorável, visando à proteção exclusiva da pessoa humana, e não os interesses da pessoa legal, em uma análise de cada caso. Ainda, o Tribunal opinou sobre um dos requisitos de admissibilidade perante a Corte: o exaurimento dos recursos da jurisdição interna via pessoa jurídica. Com o intuito de não criar embaraços processuais para a defesa da pessoa humana, a Corte entendeu que é possível que seja preenchido o citado requisito, mesmo que seja através de uma pessoa moral.

A emissão da opinião consultiva não foi realizada de forma unânime pelos magistrados, existindo um voto dissidente do juiz Alberto Pérez Pérez, que apesar de concordar que as pessoas jurídicas não estão legitimadas perante a Corte, discordou que tal possibilidade possa ser conferida aos sindicatos, pois a Convenção seria taxativa no sentido de abranger somente as pessoas físicas. Da mesma forma, não entendeu ser possível a proteção dos direitos humanos

${ }^{61}$ PIOVESAN, Flávia. Direitos Humanos e Justiça Internacional: um estudo comparativo dos Sistemas Regionais Europeu, Interamericano e Africano. 3. ed. rev., ampl. e atual. São Paulo: Saraiva, 2012, p. 211.

Revista de Direito Brasileira | São Paulo, SP | v. 19 | n. 8 | p. 170 - 185 |Jan./Abr. 2018 
através das pessoas jurídicas ou que por intermédio destas possam ser esgotados os recursos da jurisdição interna, pois caberia somente à pessoa humana preencher esses requisitos, em seu próprio nome.

O parecer em questão reflete a importância da competência consultiva da Corte na construção dos Direitos Humanos, analisando o alcance da Convenção Americana com a finalidade de efetivar a proteção da dignidade humana. Nesta função interpretativa, a Corte realiza um relevante controle de convencionalidade dos ordenamentos nacionais, verificando a compatibilidade destes com os instrumentos protetivos vigentes, o que permite a melhoria do sistema como um todo.

\section{REFERÊNCIAS BIBLIOGRÁFICAS}

BUERGENTHAL, Thomas. Derecho Internacional de los Derechos Humanos: breve visión de los mecanismos. IN: PIOVESAN, Flávia. Direitos Humanos e Justiça Internacional: um estudo comparativo dos Sistemas Regionais Europeu, Interamericano e Africano. 3. ed. rev., ampl. e atual. São Paulo: Saraiva, 2012.

CONSELHO DA EUROPA. Convenção Europeia dos Direitos Humanos, 1950.

CONSELHO DA EUROPA. Protocolo Adicional à Convenção Europeia dos Direitos Humanos, 1952.

CORREIA, Thereza Rachel Couto. Corte Interamericana de Direitos Humanos: repercussão jurídica das opiniões consultivas. Curitiba: Juruá, 2008.

CORTE INTERAMERICANA DE DIREITOS HUMANOS. El efecto de las reservas sobre la entrada em vigencia de la Convención Americana sobre Derechos Humanos. Opinião Consultiva OC-2/82 de 24 de setembro de 1982. Serie A No. 2.

CORTE INTERAMERICANA DE DIREITOS HUMANOS. Garantías judiciales en estados de emergência. Opinião Consultiva OC-9/87 de 6 de outubro de 1987. Serie A No. 9.

CORTE INTERAMERICANA DE DIREITOS HUMANOS. Opinião Consultiva OC 3/83 de 8 de setembro de 1983.

CORTE INTERAMERICANA DE DIREITOS HUMANOS. Opinião Consultiva OC 16/99 de 1 de outubro de 1999.

CORTE INTERAMERICANA DE DIREITOS HUMANOS. Opinião Consultiva OC 17/02 de 28 de agosto de 2002.

CORTE INTERAMERICANA DE DIREITOS HUMANOS. Parecer Consultivo OC 22/16 de 26 de fevereiro de 2016.2 Disponível em: http://www.corteidh.or.cr/docs/opiniones/seriea_22_esp.pdf.

CORTE INTERAMERICANA DE DIREITOS HUMANOS. Regulamento da Corte Interamericana de Direitos Humanos, 2000.

Diccionario de la lengua española de la Real Academia Española, 23. ${ }^{a}$ ed. Madrid: Espanha, 2014. Disponível em: http://dle.rae.es/?id=SjUIL8Z. 
HANASHIRO, Olaya Sílvia Portella. O Sistema Interamericano de Proteção aos Direitos Humanos. São Paulo: Universidade de São Paulo/Edusp, 2001.

JAYME, Fernando Gonzaga. A relação entre o Sistema Interamericano de proteção dos Direitos Humanos e o Direito Interno. Rev. Fac. Direito UFMG, Belo Horizonte, n. 53, jul./dez. 2008.

Nikken, Pedro. La Competencia Consultiva de la Corte Interamericana de Derechos Humanos. In: El Sistema Interamericano de Protección de los Derechos Humanos en el Umbral del Siglo XXI. San José de Costa Rica: Corte Interamericana de Derechos Humanos, 2001.

ORGANIZAÇÃO DAS NAÇÕES UNIDAS. Convenção de Viena sobre o Direito dos Tratados, 1969.

ORGANIZAÇÃO DAS NAÇÕES UNIDAS. Convenção Internacional sobre a Eliminação de todas as formas de Discriminação Racial, 1965.

ORGANIZAÇÃO DAS NAÇÕES UNIDAS. Pacto Internacional dos Direitos Civis e Políticos, 1966.

ORGANIZAÇÃO DA UNIDADE AFRICANA. Carta Africana dos Direitos Humanos e dos Povos, 1981.

ORGANIZAÇÃO DOS ESTADOS AMERICANOS. Carta da Organização dos Estados Americanos, 1967.

ORGANIZAÇÃO DOS ESTADOS AMERICANOS. Convenção Americana sobre Direitos Humanos, 1969.

ORGANIZAÇÃO DOS ESTADOS AMERICANOS. Convenção Interamericana sobre Personalidade e Capacidade de Pessoas Jurídicas no Direito Internacional Privado, 1984.

ORGANIZAÇÃO DOS ESTADOS AMERICANOS. Página institucional. Disponível em: <http://www.oas.org/pt/sobre/quem_somos.asp>. Acesso em: 23 de fev. de 2017.

ORGANIZAÇÃO DOS ESTADOS AMERICANOS. Protocolo Adicional à Convenção Americana sobre Direitos Humanos em Matéria de Direitos Econômicos, Sociais e Culturais, 1988.

ORGANIZAÇÃO INTERNACIONAL DO TRABALHO. Declaração da Organização Internacional do Trabalho sobre os princípios e direitos fundamentais no trabalho e seu seguimento, 1998.

PASQUALUCCI, Jo. M. Advisory Practice of the Inter-American Court of Human Rights: Contributing to the Evolution of International Human Rights Law. 38 STAN. J. INT'L L. 249, 2002.

PIOVESAN, Flávia. Direitos Humanos e Justiça Internacional: um estudo comparativo dos Sistemas Regionais Europeu, Interamericano e Africano. 3. ed. rev., ampl. e atual. São Paulo: Saraiva, 2012. 
SILVA XAVIER, Heidy de Abreu. O Brasil na Corte Interamericana de Direitos Humanos. Brasília, 2009. Originariamente apresentada como trabalho de conclusão de curso da Universidade Católica de Brasília.

TRINDADE, Antônio Augusto Cançado. Tratado de Direito Internacional dos Direitos Humanos. Vol. II. Porto Alegre: Sergio Antônio Fabris Editor, 1999.

VEADO, Luíza Drummond. A Opinião Consultiva 22/16: titularidade de direitos de pessoas jurídicas no Sistema Interamericano. Revista Eletrônica de Direito Internacional, ISSN 19819439, vol.19, jul./dez., 2016. 